\title{
Bibliometric Overview of Trends in Contemporary Brand Management
}

\author{
Jana Kliestikova ${ }^{1, *}$, Maria Kovacova ${ }^{1}$ \\ ${ }^{1}$ University of Zilina, Faculty of Operation and Economics of Transport and Communications, \\ Department of Economics, Univerzitna 1, 01026 Zilina, Slovak Republic
}

\begin{abstract}
Contemporary brand management theory is fragmented. On the one hand, this is very natural as the plurality of approaches is vital for constructive dialogue between scientists, but on the other hand, excessive diversity in theory causes confusion of marketing managers and disengagement of main topics in scope of brand value building and management. This fact can be considered as a significant barrier in development of branding practice. It is because of the challenges in implementation of current trends which are hard to be identified and coordinated so the synergic effect could be reached. We assume, that systemization of scientific literature is eligible to remove this handicap. From methodological point of view, it has been used VOSviewer as a basic research platform. It is a software tool for constructing and visualizing bibliometric networks. We have found out, that there are these hot topics in the scope of brand management: 1) brand perception; 2) brand elements; 3 ) branding; 4) brand community; 5) progressive tools and 6) strategic branding. Based on these finding, it is possible to focus on main trends in contemporary scientific literature dedicated to the issue of brand value building and managing and to identify current trends in more effective way.
\end{abstract}

\section{Introduction}

Existence of many trends in contemporary research of managerial issues indicates dynamics of this field. [1] On the one hand, this dynamics can be considered as a sign of importance and multi aspect view of focused topics but on the other hand, this dynamics and its symptoms makes orientation in the topic more difficult - not only for managerial practice but also for the scientists. Thus, the homogeneity of scientific schools is endangered what results to the slowdown of the progress. This state is quite paradoxical as obvious dynamics doesn't mean the development of the selected issue in the positive way of meaning. [2] Thus, the identification of significant trends is vital from the long term point of view. Optimal way how to reach actual overview is to provide complex literature visualization through bibliometric networks. [3] This idea is not original, as there were similar efforts in the scientist society so far but the essence of bibliometric networks identification has been

\footnotetext{
*Corresponding author: jana.kliestikova@fpedas.uniza.sk
} 
focused mainly on the verification of significant position of previously identified scientific school, not to identify relevant scientific schools in general.

In 2012, it was published first exploratory study aimed to produce bibliometric indicators that would represent the scientific literature on "global brand positioning," published in the last five years (2007-2011), based on the selected journals (Journal of International Marketing, The Journal of Consumer Marketing, Journal of Marketing Research and Journal of Product \& Brand Management). [4] Subsequently, it has been paid attention to the area of consumer brand relationships research by investigating not only journals for business and management, but also applied psychology and communication. [5] Glinska aimed to identify the most popular areas of scientific research in the domain of place branding on the basis of bibliometric data of scientific papers published in Scopus database between 2000 and 2017. [6] Another brand management trend verified by bibliometric analysis has been brand personality. Radler aimed to deconstruct 20 years of research on brand personality by systematically reviewing the extant literature and identifying relevant research gaps. Based on the citation map, five research clusters within brand personality literature were identified. [7] Similarly, one of the most recent papers in brand management bibliometric overview has provided a global view of the research that has been conducted regarding brand personality by using the Core Collection of the Web of Science (WoS) as a reference. [8] Verifying approach to the trends in brand management was applied also by Ma et al. who provided bibliometric analysis of place branding. [9]

Another trend in bibliometric research consists in regional focusing on the brand management hot topics. [10] Unfortunately, neither this approach is convenient although it eliminates the lack of previous one which consists in verification of relevance of selected brand management topic. The reason is that despite, brand management essential schools are detected, it happens only in selected region and thus, its results cannot be considered as generally valid. It is because the regional specifics in brand management have been already proved. [11] This fact does not make able the creation of continual branding theory, where first global trends should be detected and subsequently, these trends and new patterns should be modified in scope of specific regional conditions. [12]

In 2013, the only one complex study of brand management trends has been realized so far. It has examined the citations used in the global branding literature, and evaluated the knowledge structure of this area of research to date. The bibliometric analysis involved an examination of 120 global branding articles in business-related research. The conceptual framework developed incorporates five areas with important implications for the future development of global branding as an area of inquiry. These major research topics in the global branding literature are international branding strategy, brand positioning, brand/country origin, brand concept-image, and brand performance. [13]

Taking into account the dynamic of research in the field of brand management, obtained data are not actual and it is important to provide ideologically identical analysis with the modern analytical instruments to verify or replace detected brand management trends.

\section{Paradigmatic approach to the brand management}

The paradigmatic approach to brand management arises from the need of trends identification in the context of brand value building and managing in scope of individual markets, whether from regional or product perspective is applied. [14] For the purposes of terminological harmonization with the philosophical dimension of paradigm research of brand management, we state that we understand the paradigm in the sense of the T.S. Kuhn, who was a representative of the theory of historical dynamics of scientific knowledge. According to this theory, the paradigm is a spontaneous change of a certain model caused by the fact that the evolution of science does not take place in continuous changes, but 
through revolutionary processes. [15] He based his theory on the assumption of alternating stages of so-called normal science (recognition of a certain paradigm) and so-called critical stages (when, due to the accumulation of unsolved problems, there is a revolution creating multiple competing paradigms). The dynamics of brand management research is accelerating in the 1980s. Heding et al. report that, since 1985, two dominant paradigms have been identified in the context of brand building and value management (see Table 1). [16]

Table 1. Brand management paradigms according to Heding et al.

\begin{tabular}{|c|c|c|c|}
\hline $\begin{array}{c}\text { Brand management } \\
\text { paradigm }\end{array}$ & Focus & Period & $\begin{array}{c}\text { Approach to the } \\
\text { brand management }\end{array}$ \\
\hline positivist & company / sender & $1985-1992$ & economic \\
\hline & & & identity \\
\hline & human / receiver & $1993-1999$ & consumer-based \\
\hline & & & personality \\
\hline & & & relational \\
\hline interpretive & cultural / context & $2000-$ now & community \\
\hline & & & \\
\hline
\end{tabular}

The positivistic paradigm is based on the assumption that the brand is a product of purposeful marketing activity of the company. So, it is possible to communicate with its passive recipient (consumer) via controlled way and thus, significantly affect the brand value, which is subjectively perceived by the consumer. The brand value is thus understood as a result of the systematic activity of the company. In this sense, authors state that the brand itself is an easy-to-manipulate inanimate artefact (the so-called overproduct created by its owners / managers and can be placed, segmented and used to create a predefined image of the product or business itself ). [17]

The economic approach is based on perception that brand management is an autonomous area of marketing management which focuses on verifying the functionality of traditional marketing concepts in the context of brand value building and management. Brand management is thus identified with so called management of changes in scope of examining the reaction dynamics between consumer perceived brand value and traditional manipulations of marketing mix tools (i.e., price change, distribution network extension, intensification of sales promotion, etc.). In brand management, this approach is specific by functionalist brand perspective as well as a perfectly rational consumer assumption based on the existence of "Homo Oeconomicus". According to this theory, the consumer chooses the brand that maximizes its utility at a given price. [18] Zaichkowsky states that the theoretical apparatus is based on the concept of transaction marketing, where the exchange between the brand and the consumer consists in isolated transactions rather than in a continuing relationship. [19]

According to Balmer, the corporate identity approach has logically emerged from the economic approach as a response to questioning the uniformity of consumer responses in implementing procedures resulting from the quantitative data gathered in the context of the consumer rationality theory. [20] This approach is based on a strong and coherent brand identity. Its creation is situated into the business rather than the product level, and the 
attention shifts from focusing on the visual representation of product brands to the corporate identity. While this is evolutionarily the second oldest approach to brand management, its impact on science schools is still significant, especially in the European science and research area. Applying a corporate identity approach, the brand is primarily perceived as an entity created by the manager, accepting the fact that identity is not permanent but context-dependent.

The consumer-based approach is a breakthrough approach based on understanding the brand as a cognitive construct in the mind of the consumer. It is assumed that a strong brand has a strong and unique position in the minds of consumers which is capable of evoking favourable associations. Thus, in the context of brand management, managers' attention is shifted from company to consumer as the dominant attribute of brand value. So, it is vital to adapt the processes of brand value building and management that have been used so far to this attribute. [21] Louro and Cunha report that this phase is still characterized by a linear model of communication, as it remains assumed that managers are able to direct the consumer and the subjectively perceived brand value in a businessconforming direction using appropriate marketing tools. [22] In cognitive psychology, it is assumed that the human brain operates on the basis of input and output data similarly to a computer, and the focus is thus on how knowledge (in the form of mental representations) is stored and subsequently retrieved from memory. Similarly, the limitation of processing capacity of the human brain is assumed, implying the need of application of the most efficient communication concept. Indeed, in order to speak about the value based on a subjective consumer perception, brand awareness must be present in his mind. The basis for determining brand value is the comparative framework by which the strength and uniqueness of brand associations in the mind of the consumer can be compared with competing brands and their position.

The personality approach is based on the assumption that consumers tend to assign human characteristics to a brand, creating a platform for easier identification with it. Ahuvia states that the key attribute of brand value creation is human personality and consumer identity, as well as their personalized expression. [23] The symbolic contents that a brand can offer to consumers, expressed through certain brand characteristics, are considered parameters of the brand value. The main function of a brand is not to provide utilitarian attributes and benefits as in an economic approach, but to enable consumers to express themselves by providing symbolic value signalled by the brand. The brand value is then determined by the degree to which there is a match between the brand personality and the consumer personality.

The relationship approach consists in the development of personality approach. As Aggarwal states, the idea that brand is a viable relationship partner is based on the same metaphor of human brand characteristics. [24] The essence of this approach, unlike the previous one, lies primarily in the philosophical dimension of brand management referring to the tradition of existentialism and methods of phenomenological character. By applying this approach, the "internal reality" of the consumer becomes valid and valuable data material. The phenomenological perspective emphasizes a holistic view on the consumer and is therefore interested in many aspects that are not directly related to immediate consumer behaviour. Stern et al. state that the traditional concept of creating and maintaining relationships between people is extended in this approach in terms of animism (attribution of human characteristics to an inanimate object) by the phenomenon of the relationship between man and brand. [25] However, it is not only the simple identification of the dimensions of 'consumer-brand' relationships, but also their quality and volatility when the change of relevant factors occurs.

The interpretative paradigm understands the brand and the process of brand value building and managing as a logical consequence of the interaction between its creator and 
the active consumer. Dineen and Allen consider the brand as a complex entity characterized by many of the characteristics of living beings (thus having their own personality as a prerequisite for establishing and maintaining relationships with individuals in society). [26]

The community approach is based on anthropological research of so-called brand communities. According to this approach, brand value is created in these communities so that the brand serves as a key element of social interaction between consumers. This has become a prerequisite for brand value building and managing in many cases, especially after the Internet has fundamentally changed the market. In a community-based approach, managers focus on "autonomous" consumer groups which are able to collectively influence marketing actions and potentially develop the brand in a direction that will shape the market regardless of the original managerial intent. [27] Brown et al. report that brand management has shifted from the concept of linear communication to the level of enterprises of non-content-based communication content with a significant impact on the brand's perceived value across communities. [28] The community approach is based on the "triad" of entities - brand, consumer and community. This relationship means that consumers must interact not only with the brand but also with each other.

The cultural approach considers the brand as a cultural artefact. Arnould and Thompson argue that the basic pillar of this approach is the so-called phenomenon of iconic brand. [29] In order to brand value building and managing, the attention of marketers is shifted from accentuating the relationship with customer to a macroeconomic relationship with the company. This approach focuses on what brands do for culture and what culture can do for brands. The core of the cultural approach is both iconic brands and countercultural movements focused on brand value building and management in the full complexity of the mutual functional mechanisms of influencing society and participating in the creation of cultural values and schemes. According to Holt, the consumer is no longer understood as "Homo Oeconomicus", but as "Homo Mercans", who is making his choice under the pressure of complex cultural meanings and interactions. [30]

Paradigmatic approach is very closely connected with the bibliometric analysis of the brand management. In general, it creates an essential platform for detection of trends in the brand management research. Thus, consumer - brand relationship paradigm are the core of investigation in scope of new brand management trends detection. By considering a chain of effects' model, Giovanis aims to integrate two brand commitment paradigm's perspectives with service evaluation theory, representing the attitudinal and behavioral aspects of the relationship building process, to better explain the way consumers relate to a service brand. [31] Gomez-Suarez et al. state that consumer-brand relationships encompass several dimensions, most of which have attracted growing research attention during the last years. Building these relationships is especially important in the marketing 3.0 era, where it is suggested that customers will choose those brands that satisfy their deepest needs. With these ideas in mind, their article provides a review of two key concepts implied in such relationships: brand love and customer engagement. Although both conceptions focus on different stages of consumer-brand relationships, they actually cover different perspectives on the same process. Moreover, they come from diverse conceptual paradigms: whilst brand love comes from the psychology discipline, engagement derives from diverse areas of the marketing field (e.g., the service-dominant logic perspective). [32] Recently, mainly the community approach is examined due to the social media expansion as a modern platform for its implications. [33,34]

\section{Methodology}

The idea of visualizing bibliometric networks, often referred to as science mapping, has received serious attention since the early days of bibliometric research. Visualization has 
turned out to be a powerful approach to analyze a large variety of bibliometric networks, ranging from networks of citation relations between publications or journals to networks of co-authorship relations between researchers or networks of co-occurrence relations between keywords. Over time, researchers have started to analyze larger and larger networks, leading to the need for more advanced visualization techniques and tools. At the same time, professional users of bibliometrics, for instance research institutions, funding agencies, and publishers, have become more and more interested in bibliometric network visualizations. To make bibliometric network visualizations available to a wider public, both inside and outside the bibliometric research community, researchers have developed a number of software tools, most of which are freely available. Nowadays, widely used are these two: VOSviewer and CitNetExplorer. VOSviewer is a tool that we have developed over the past few years and that offers in a relatively easy way the basic functionality needed for visualizing bibliometric networks. [35]

The VOSviewer provides distance-based visualizations of bibliometric networks. By default, VOSviewer therefore displays only the nodes in a bibliometric network and does not display the edges between the nodes. In the visualizations provided by VOSviewer, the distance between two nodes approximately indicates the relatedness of the nodes. By providing distance-based visualizations rather than graph-based ones, VOSviewer is especially suitable for visualizing larger networks. Because of its strong focus on visualization, VOSviewer offers less functionality for analyzing bibliometric networks than other tools. However, VOSviewer does have some special text mining features.

We've applied VOSviewer on the data obtained in Web of Science database since year 2016 to be sure that only hot topics are included to detect trends in scope of brand value building and management. We didn't focus only on top journals in this field, but we've applied key words approach regardless source of the paper. Thus, brand management has been investigated while to criteria to the inclusion of the topic obtaining this key words has been its appearance in more than twelve sources. Based on this, clustering could be provided. The basic dataset has been formed by more 3000 papers.

\section{Results and discussion}

The bibliometric map which is a final output of provided analysis of scientific literature through VOSviewer is shown at the figure 1.

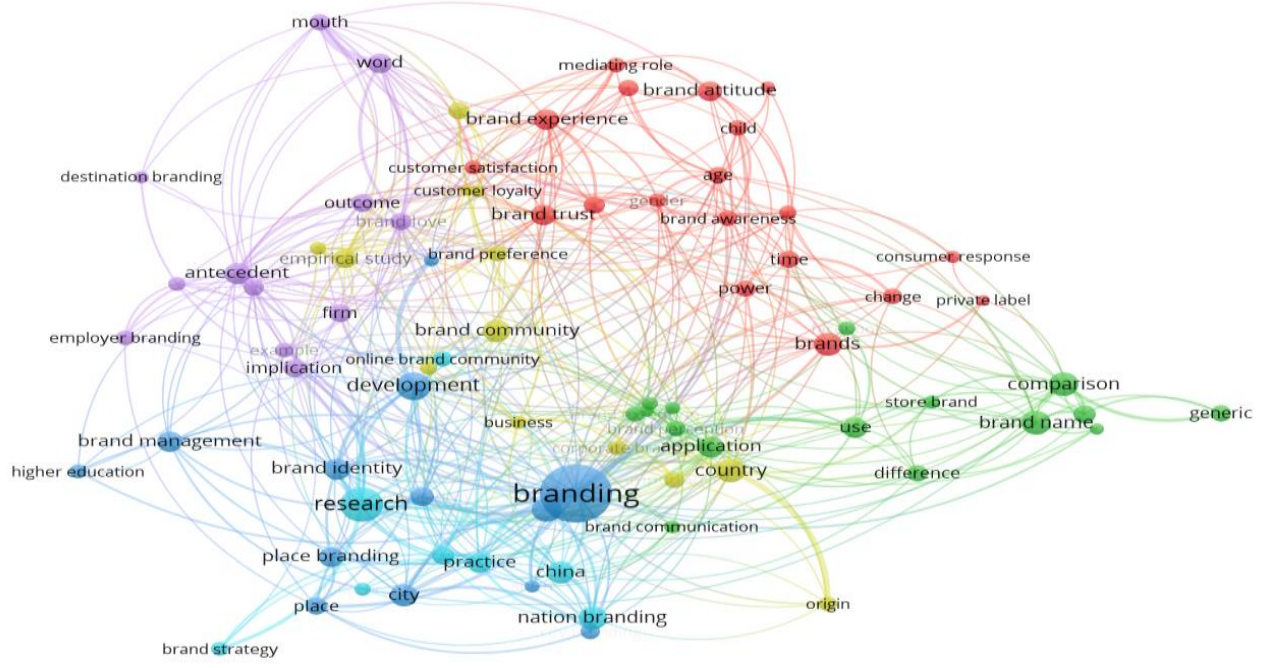

Fig. 1. Bibliometric map 
According to this visualization, we can state that there are these trends in the scope of brand management scientific literature:

1) brand perception - brand experience, brand attitude, brand trust, brand awareness...,

2) brand elements - brand name, comparison, difference, store brand, application...,

3) branding - brand identity, city, place branding, development, brand management...,

4) brand community - country, brand preference, origin, online brand community...,

5) progressive tools - employer branding, destination branding, implication...,

6) strategic branding - research, practice, brand strategy... .

All these topics can be considered as relevant from the point of view of future development of scientific theory in the field of brand management. Thus, these topics should be the core of contemporary research activities in general and in scope of the need of their modification according to the market specifics (not only product but regional as well). From the paradigmatic point of view, the dominance of community approach is obvious. This fact is in contrast with evolution of interpretative paradigm. According to it, cultural approach should be one of the identified trends. This state is the result of subjective factor of provided research where the identified areas have to be titled by the authors. Thus, the cultural approach is not missing in the list of identified trends as it is only very recent trend which doesn't have enough support in the scientific literature so far to be considered as an autonomous trend and nowadays, it is partially included in the wider topics. In comparison with previous research, we can state that there is no more the same structure of key topics (brand perception, brand elements, branding, brand community, progressive tools and strategic branding according to own research and international branding strategy, brand positioning, brand/country origin, brand concept-image, and brand performance according in 2013). [13] Previously relevant topic like international branding strategy or brand/country origin have been incorporated into wider topics nowadays. This fact indicates the need of systematic evaluation of trends in contemporary brand management provided in the light and shadow of bibliometric overview. Similarly, neither topic previously considered as relevant and autonomous in scope of brand value building and managing, haven't been proved. We refer mainly to place branding and brand personality. $[4,6,7,8,9]$ Also these topics are nowadays a part of other more coherent issues of brand management. So, we can state that brand management bibliometric overview indicates the shift to wider theoretical entities which seem to be more coherent in time.

\section{Conclusion}

The aim of the paper was to systemize the scientific literature published in scope of brand value building and management in relevant database Web of Science and to identify key topics which indicate the development of the fragmented branding theory. We've assumed that on the one hand, this fragmentation is very natural as the plurality of approaches is vital for constructive dialogue between scientists, but on the other hand, excessive diversity in theory causes confusion of marketing managers and disengagement of main topics in scope of brand value building and management. We have found out, that there are these hot topics in the scope of brand management: 1) brand perception; 2) brand elements; 3) branding; 4) brand community; 5) progressive tools and 6) strategic branding.

This paper is an outcome of the science project APVV-15-0505: Integrated model of management support for building and managing the brand value in the specific conditions of the Slovak Republic. 


\section{References}

1. A. Domanska, Cooperation between knowledge-based institutions and business: empirical studies and network theories. Forum Scientiae Oeconomia 6, 4, 81-94 (2018)

2. N. Shpak, N. Seliuchenko, V. Kharchuk, N. Kosar, W. Sroka, Evaluation of product competitiveness: A case study analysis. Organizacja 52, 2, 107-125 (2019)

3. L. Gajanova, M. Nadanyiova, D. Moravcikova, The use of demographic and psychographic segmentation to creating marketing strategy of brand loyalty. Scientific Annalals of Economics and Business 66, 1, 65-84 (2019)

4. V. Sciasci, S.F.A. Garcia, L.C.D.A. Galli, Positioning for global brands: A bibliometric study of scientific production in the area. Revista Brasileira De Marketing 11, 2, 69-95 (2012)

5. M. Fetscherin, D. Heinrich, Consumer brand relationships research: A bibliometric citation meta-analysis. Journal of Business Research 68, 2, 380-390 (2015)

6. E. Glinska, E.J. Tomaszewska, Main areas of place branding scientific research Bibliometric analysis. Economic and Social Development (ESD): Managerial Issues in Modern Business 86-95 (2017)

7. V.M. Radler, 20 years of brand personality: A bibliometric review and research agenda. Journal of Brand Management 25, 4, 370-383 (2018)

8. G.R. Llanos-Herrera, J.M. Merigo, Overview of brand personality research with bibliometric indicators. Kybernetes 48, 3, 546-569 (2019)

9. W.T. Ma, D. Schraven, M. de Bruijne, M. de Jong, H.Y. Lu, Tracing the origins of place branding research: A bibliometric study of concepts in use (1980-2018). Sustainability 11, 11, 2999 (2018)

10. M.D. Wendeling, P.F.M. Gomes, I.R. Troccoli, Marketing studies about brands: A bibliometric research on the 2007-09 enanpads. Gestao e Desenvolvimento 10, 1, 7185 (2013)

11. A. Krizanova, L. Gajanova, M. Nadanyiova, Design of a CRM level and performance measurement model. Sustainability 10, 7, 2567 (2018)

12. E. Stonkute, J. Vveinhardt, W. Sroka, Training the CSR sensitive mind-set: The integration of CSR into the training of business administration professionals. Sustainability 10, 3, 754 (2018)

13. B.R. Chabowski, S. Samiee, G.T.M. Hult, J. A bibliometric analysis of the global branding literature and a research agenda. Journal of International Business Studies 44, 6, 622-634 (2013)

14. V. Braciniova, K. Matusinska, Marketing mix of financial services from the customers perspective. Forum Scientiae Oeconomia 5, 4, 35-48 (2017)

15. J. Popp, J. Olah, A. Kiss, A. Temesi, C. Fogarassy, Z. Lakner, The socio-economic force field of the creation of short food supply chains in Europe. Journal of Food and Nutrition Research 58, 1, 31-41 (2019)

16. T. Heding, Ch.F. Knudtzen, M. Bjerre, Brand Management: Research, Theory and Practice (Routledge, 2016)

17. J. Hyun, A. Fairhurst, Understanding consumers' purchasing behavior of ethnically disparate products. Journal of Consumer Behaviour 17, 1, E114-E126 (2018)

18. S. Bhat, S.K. Reddy, Symbolic and functional positioning of brands. Journal of Consumer Marketing 15, 1, 32-43 (1998) 
19. J.L. Zaichkowsky, Consumer behavior: Yesterday, today, and tomorrow. Business Horizons 34, 3, 51-58 (1991)

20. J.M.T. Balmer, Corporate identity and the advent of corporate marketing. Journal of Marketing Management 14, 8, 963-998 (1998)

21. K.L. Keller, Marketing Management 14, 5, 18-23 (2005)

22. M.J. Louro, P.V. Cunha, Brand management paradigms. Journal of Marketing Management 17, 7-8, 849-875 (2001)

23. A.C. Ahuvia, Beyond the extended self: Loved objects and consumers' identity narratives. Journal of Consumer Research 32, 1, 171-184 (2005)

24. P. Aggarwal, The effects of brand relationship norms on consumer attitudes and behavior. Journal of Consumer Research 31, 1, 87-101 (2004)

25. B.B. Stern, C.J. Thompson, E.J. Arnould, Narrative analysis of a marketing relationship: The consumer's perspective. Psychology \& Marketing 15, 3, 195-214 (1998)

26. B.R. Dineen, D.G. Allen, Third party employment branding: Human capital inflows and outflows following "best places to work" certifications. Academy of Management Journal 59, 1, 90-112 (2008)

27. R. Algesheimer, U.M. Dholakia, A. Herrmann, The social influence of brand community: Evidence from European car clubs. Journal of Marketing 69, 3, 19-34 (2005)

28. S. Brown, R.V. Kozinets, J.F. Sherry jr., Teaching old brands new tricks: Retro branding and the revival of brand meaning. Journal of Marketing 67, 3, 19-33 (2003)

29. E.J. Arnould, C.J. Thompson, Consumer culture theory (CCT): Twenty years of research. Journal of Consumer Research 31, 4, 868-882 (2005)

30. D.B. Holt, Why do brands cause trouble? A dialectical theory of consumer culture and branding. Journal of Consumer Research. 29, 1, 70-90 (2002)

31. A. Giovanis, J. Consumer-brand relationships' development in the mobile internet market: evidence from an extended relationship commitment paradigm. Journal of Product and Brand Management 25, 6, 568-585 (2016)

32. M. Gomez-Suarez, M.P. Martinez-Ruiz, N. Martinez-Caraballo, Consumer-brand relationships under the marketing 3.0 paradigm: A literature review. Frontiers in Psychology 8, 252 (2017)

33. J. Ul Islam, Z. Rahman, The impact of online brand community characteristics on customer engagement: An application of Stimulus-Organism Response paradigm. Telematics and Informatics 34, 4, 96-109 (2017)

34. S. Kamboj, B. Sarmah, S. Gupta, Y. Dwivedi, Examining branding co-creation in brand communities on social media: Applying the paradigm of Stimulus-OrganismResponse. International Journal of Information Management 39, 169-185 (2018)

35. N.J. Van Eck, L. Waltman, Measuring scholarly impact: Methods and practice (Springer, 2014). 